\title{
LAS PRIMERAS ALMONEDAS DE TÍTULOS NOBILIARIOS EN PERÚ (1681-1703)
}

Ismael Jiménez Jiménez ${ }^{1}$. Universidad de Sevilla. DOI: 10.17533/udea.tempus.n6a03

\section{Resumen}

En el último tercio del siglo XVII la venalidad alcanzó sus mayores cotas y aquellos criollos anhelantes de reconocimiento social tuvieron su oportunidad. Los abultados gastos de la Monarquía Católica y algún compromiso extraordinario provocaron que a las almonedas americanas comenzasen a llegar títulos nobiliarios. Éste fue el momento esperado por aquellos indianos con capitales suficientes como para conseguir su intitulación mediante la compra. Sin embargo, no todo se limitó a una simple transacción. Como revelan las fuentes del Archivo General de Indias, a los nuevos titulados les surgieron problemas económicos, burocráticos e incluso de prestigio. En las siguientes páginas nos proponemos explicar estos primeros procesos venales y conocer las cuantías desembolsadas por los primeros nobles peruanos.

Palabras clave: venalidad, almoneda, nobleza, Perú, siglo XVII.

Abstract In the last third of the seventeenth century the venality reached its highest quotas and these creoles yearning for social recognition had their opportunity. The huge amount of expenditure incurred by the Catholic Monarchy and some extraordinary compromise caused that the American auctions began to arrive titles of nobility. This was the time expected by the indians with sufficient capital to obtain their degree through the purchase. However, not everything is limited to a simple transaction. As the sources of the General Archive of Indias reveal, the new graduates were face with economic, bureaucratic and even prestige problems. The propose in the following pages is to explain these first sales processes and to know the amounts disbyrsed by the first peruvian nobles.

Key words: venality, auction, nobility, Peru, XVII century.

\footnotetext{
${ }^{1}$ Doctor con Mención Internacional en Historia por la Universidad de Sevilla (España). Investigador del Grupo “Andalucía y América Latina: marco historiográfico y desarrollo económico y cultural” (HUM371). Asistente honorario del Departamento de Historia de América de la Universidad de Sevilla.
} 


\section{Introducción.}

El Virreinato del Perú durante la segunda mitad del siglo XVII no fue un territorio ajeno a los fenómenos que estaban teniendo lugar en el resto de los dominios de la Monarquía Católica. Al igual que en los demás, en la jurisdicción limeña la práctica de la venalidad experimentó una tendencia creciente durante todo el Seiscientos. Cargos, oficios, plazas, magistraturas, dignidades, etc. fueron puestas en almoneda hasta el grado de que estas ventas alcanzaron los estratos más elevados de la sociedad estamental, la nobleza titulada, y de la administración indiana, el nombramiento como virrey. De esta manera, como señaló Domínguez Ortiz, a finales del siglo XVII se había tocado el techo de la venalidad, pues todo aquello que podía ser enajenado, lo fue ${ }^{2}$. Este hecho, que la almoneda copase dichas cimas, junto con su pervivencia dilatada, sólo puede ser explicado por los beneficios suculentos y, casi, constantes que aportaban a la Real Hacienda ${ }^{3}$. Sin embargo, no puede sostenerse la venalidad sólo en el ingreso que supuso al Erario, sino que otros aspectos, como la flexibilidad necesaria para la conservación de los territorios indianos, también han de estar presentes en el análisis de estos hechos. Así pues, pretendemos en las siguientes páginas desmenuzar la forma y el proceso utilizado por los primeros súbditos americanos, específicamente los residentes en el distrito de la Audiencia de Lima, para obtener un título nobiliario. Éstos demandaron dicho estatus social a la administración metropolitana, siendo el origen de la nobleza criolla titulada y, a su vez, los precursores de un modelo que se prolongó hasta el final de la presencia hispánica en las Indias.

De un modo u otro, lo cierto fue que la Corona, en las sienes de Carlos II, hubo de hacer frente a ofertas sustanciosas por cargos indianos, ascensos sociales o títulos nobiliarios. Así, en 1666, cuando el Rey apenas tenía cinco años y sólo uno en el trono, a la regencia encabezada por su madre, Mariana de Austria, llegó un ofrecimiento de 100.000 ducados para conseguir el nombramiento como virrey del Perú. Ese mismo año había fallecido en Lima don Diego de Benavides, conde de Santisteban del Puerto y virrey

\footnotetext{
2 Antonio Domínguez Ortiz, "Un virreinato en venta", Mercurio Peruano, no. 453 (1965): 51.

${ }^{3}$ Pilar Ponce-Leiva, "El valor de los méritos. Teoría y práctica política en la provisión de oficios (Quito, 1675-1700)", Revista de Indias LXXIII, (2013): 342.
} 
peruano, y para sucederlo Manuel Enríquez presentó la citada propuesta ${ }^{4}$. Este individuo sabía a lo que aspiraba al presentarse para comprar el puesto, pues era hijo de quien también había sido virrey, el conde de Alba de Liste, y, además, hermano de Juan Enríquez y Enrique Enríquez, general y almirante de la Armada del Mar del Sur respectivamente ${ }^{5}$. Es decir, tenía pleno conocimiento de los beneficios que podía acarrear en un futuro el desembolso de los 100.000 ducados por el virreinato. Aunque la Corona acabó desestimando la oferta de Manuel Enríquez y nombrando como virrey al conde de Lemos, otros personajes no desistieron en su intento de, mediante la venalidad, ocupar la cima del gobierno peruano. En 1696 Francisco José Núñez de Villavicencio y Sandier ofreció a la Corona, a modo de donativo, 250.000 pesos a cambio de ser nombrado virrey del Perú. Para entonces, este individuo ya sabía de los mecanismos de la venalidad, pues en 1668 consiguió por esta vía el título de conde de Cañete de Pinar. Sus caudales procedían, por rama materna, de comerciantes de origen flamenco asentados en Sevilla, lo cual supuso una buena fuente de crédito para conseguir ambos nombramientos. Sin embargo, a pesar de que consiguió, gracias a la pecunia, que el Consejo de Indias le facultase para ocupar el Palacio virreinal de Lima, la fatalidad se cruzó en su camino. Mientras Núñez de Villavicencio permanecía en Acapulco para embarcar en la Armada del Mar del Sur rumbo al Callao, cayó enfermo y falleció el 20 de abril de $1697^{6}$.

Por lo anterior, no es exagerado decir que la segunda mitad del siglo XVII estaba presentando altas cotas de venalidad. Así pues, como puede deducirse de las operaciones señaladas, el principal mérito para alcanzar un cargo e incluso un título nobiliario fue la entrega de determinados peculios ${ }^{7}$. Nos encontramos, por tanto, ante un panorama diferenciado del existente en la primera parte de la centuria, que afecta por igual tanto a la Península como a las Indias. De esta manera se observa, en cuanto a la enajenación de títulos, que se pasa a finales del reinado de Felipe III de la existencia de 307 nobles

\footnotetext{
${ }^{4}$ Guillermo Lohmann Villena, El conde de Lemos. Virrey del Perú (Madrid: Escuela de Estudios Hispanoamericanos, 1946), 19.

${ }^{5}$ Ismael Jiménez Jiménez, "Niños con poder: mandos pueriles en el Virreinato del Perú en la segunda mitad del siglo XVII", en Temas americanistas: historia y diversidad cultural, coords. Sandra Olivero Guidobono y José Luis Caño Ortigosa (Sevilla: Universidad de Sevilla y Diputación Provincial de Sevilla, 2015), 126128.

${ }^{6}$ Guillermo Lohmann Villena, "Notas sobre el conde de Cañete, virrey del Perú", Revista de Indias III, (1942): 552-554.

${ }^{7}$ Francisco Andújar Castillo, "Hacerse noble a finales del siglo XVII. Las contradicciones de la jerarquía nobiliaria", en Construyendo Historia. Estudios en torno a Juan Luis Castellano, eds. Antonio Jiménez Estrella, Julián J. Lozano Navarro, Francisco Sánchez-Montes González y Margarita Ma Birriel Salcedo (Granada: Universidad de Granada, 2013), 18.
} 
titulados a la cifra de 1.047 en torno al año $1700^{8}$. Pero de este incremento tan significativo en el período 1621-1700 al reinado de Carlos II no le correspondió el total, aunque si un buen porcentaje en esta escalada venable. No obstante, la responsabilidad del gobierno de este Monarca en la inflación nobiliaria no está estimada con certeza, pues como recoge Rodríguez Hernández la concesión de títulos varía según las fuentes usadas 9 . Así, Domínguez Ortiz señaló que entre condes, marqueses y vizcondes se crearon un total de 292 títulos entre 1665 y 1700 (78, 209 y 5 respectivamente) ${ }^{10}$; Henry Kamen para el mismo periodo y títulos defiende la cifra de 328 (80, 236 y 12 en cada categoría $)^{11}$; en los registros de la propia Cámara de Castilla se han encontrado anotados 312 títulos (divididos en 84, 212, 16) ${ }^{12}$; y, más recientemente, Soria Mesa postula que se otorgaron 411 títulos nobiliarios, sin entrar a clasificarlos ${ }^{13}$. Apoyándonos en unas cifras u en otras, lo cierto es que se había producido en la segunda mitad del Seiscientos un incremento pronunciado en el más alto escalón del estamento privilegiado -el de la nobleza titulada, afectando a ambos hemisferios de la Monarquía y constituyendo una tendencia difícil de frenar. Así, por ejemplo, los esfuerzos de Felipe V por invertir la venalidad cayeron en saco roto y a final de su reinado no sólo siguieron enajenándose títulos, sino que también la gran mayoría de los asientos en las audiencias americanas eran canjeados por dinero $^{14}$

Fuesen unas cifras u otras, lo cierto es que durante el XVII se experimentó una tendencia creciente a que el Consejo y Cámara de Indias aceptasen pesos a cambio de una valoración positiva de los candidatos a las diferentes plazas americanas o para la consecución de un título nobiliario. La importancia cada vez mayor del capital para la obtención de estos objetivos provocó que, a partir de 1686, cuando la Cámara de Indias

\footnotetext{
${ }^{8}$ María del Mar Felices de la Fuente, "Recompensar servicios con honores: el crecimiento de la nobleza titulada en los reinados de Felipe IV y Carlos II", Studia Historica, Historia Moderna, no. 35 (2013): 414. ${ }^{9}$ Antonio José Rodríguez Hernández, "La creación de títulos de Castilla durante los reinados de Felipe IV y Carlos II: concesiones y ritmos", en Casas, familias y rentas. La nobleza del reino de Granada entre los siglos XV-XVIII, eds. Julián Pablo Díaz López, Francisco Andújar Castillo y Ángel Galán Sánchez (Granada: Universidad de Granada, 2010), 182.

${ }^{10}$ Antonio Domínguez Ortiz, La sociedad española en el siglo XVII, vol. 1 (Madrid: Consejo Superior de Investigaciones Científicas, 1992), 210.

${ }^{11}$ Henry Kamen, La España de Carlos II (Barcelona: ed. Crítica, 1981), 411.

12 Rodríguez Hernández, "La creación de títulos", 182.

${ }^{13}$ Enrique Soria Mesa, La nobleza en la España moderna: cambio y continuidad (Madrid: Marcial Pons, 2007), 50-51.

${ }^{14}$ Scarlett O’Phelan, "Orden y control en el siglo XVIII. La política borbónica frente a la corrupción fiscal, comercial y administrativa", en El pacto infame. Estudios sobre la corrupción en el Perú, eds. Felipe Portocarrero Suárez (Lima: Pontificia Universidad Católica del Perú, Universidad del Pacífico e Instituto de Estudios Peruanos, 2005), 26.
} 
pasó a despachar todas las provisiones regias, no existiesen apenas puestos o privilegios que no pudiesen ser conseguidos a cambio de un desembolso. Así, entre 1674 y 1700, es decir, durante el gobierno "efectivo" de Carlos II, para las Indias se proveyeron un total de 1.026 nombramientos en 243 oficios con potestad jurídica ${ }^{15}$. O lo que es lo mismo, la última frontera de la venalidad, la de los cargos con capacidad jurisdiccional, había sido traspasada. No obstante, la venta de títulos se desmarca de la política de la Corona con respecto a otro tipo de enajenaciones, pues con estas transacciones no se buscaban aumentos directos de los ingresos de la Real Hacienda, sino evitar que sobre ella cayesen otro tipo de gastos ${ }^{16}$. En cualquier caso, en cuanto a la almoneda de títulos habremos de diferenciar entre las dos formas de venalidad más extendidas: el beneficio y la venta.

Por beneficio se entiende aquel método venal por el que el receptor de un cargo entregaba un capital determinado en la Real Hacienda, con fines diversos, pero acompañado siempre de una hoja de méritos y servicios que indicaba la idoneidad de la persona a ser provista. No obstante, en el caso de los títulos bastaba con remitir a la Corona un memorial, tener los contactos precisos y comprometer una cantidad de pesos considerables que supliese la trayectoria honorable requerida ${ }^{17}$. El beneficio fue, por tanto, el traspaso de pecunia, disimulada como donación o empréstito en algunos casos, al Fisco Regio a cambio de un nombramiento. De esta manera, ese intercambio de dinero se llegó a interpretar, para maquillar en la medida de lo posible las acciones venales, como un servicio que un particular hacía a la Corona ${ }^{18}$. Así, encontramos despachos de títulos en los que se oculta que la merced había sido conseguida gracias al dinero, a pesar de que este era su principal instrumento legitimador para ostentar tal grado ${ }^{19}$. En cualquier caso, y esto es algo remarcable dada la naturaleza de títulos nobiliarios, el beneficio de un oficio estaba limitado temporalmente, mientras que las concesiones que tratamos fueron en algunos casos vitalicias y en otros hereditarias. Por esta razón, la segunda modalidad venable apuntada, la venta, fue más ajustada al objeto tratado en este artículo. Así pues, se entiende por venta la transacción entre la Corona y un sujeto de un oficio, cargo o

\footnotetext{
15 Ángel Sanz Tapia, ¿Corrupción o necesidad? La venta de cargos de gobierno americanos bajo Carlos II (1674-1700) (Madrid: Consejo Superior de Investigaciones Científicas, 2009), 69.

16 Ramón Maruri Villanueva, "Poder con poder se paga: títulos nobiliarios beneficiados en Indias (16811821)", Revista de Indias LXIX, (2009): 208.

${ }^{17}$ María del Mar Felices de la Fuente, "Silencio y ocultaciones en los despachos de los títulos nobiliarios. Análisis crítico de su contenido”, Chronica Nova XXXVI, (2010): 249.

${ }^{18}$ Sanz Tapia, ¿Corrupción o necesidad? La venta de cargos, 53.

${ }^{19}$ Felices de la Fuente, "Silencio y ocultaciones", 232.
} 
privilegio con carácter patrimonial a cambio de una cantidad de dinero estipulada previamente $^{20}$. Por ello, mediante la venta los diferentes personajes que participaron de la almoneda pública consiguieron derechos de propiedad y transmisión sobre aquellos títulos conseguidos gracias a sus pesos.

Con estos sistemas en plena marcha y definidos en la segunda mitad del siglo XVII, la venalidad no tardó en extenderse por todos los ámbitos institucionales y sociales de la Monarquía. Buen ejemplo de ello fue el acceso desorbitado de sujetos al Consejo de Indias en calidad de consejeros, constatado meses antes del fallecimiento de Carlos II. Resultó que de diez miembros que debían componer dicho organismo, se encontraban situados en la institución, con voz, voto y sueldo, un total de diecinueve ${ }^{21}$.

Sin embargo, la gran diferencia entre la almoneda peninsular y la indiana fue la necesidad, ineludible en el caso americano, de intermediarios. Es conocido que el empleo de agentes especializados en la mediación ante la Corte allanó mucho el camino de la compra para los indianos. Estos "representantes de lo venal" se convirtieron en fundamentales, pues pasaron a monopolizar las relaciones entre oferentes y demandantes, transformando estas comisiones en una profesión lucrativa y que dependió, en buena medida, de una amplia red clientelar que garantizase la obtención del cargo, hábito o título deseado $^{22}$. Pero la disponibilidad en la almoneda y la posesión de capitales, además de los contactos necesarios, no fue un binomio correlativo a la consecución de los títulos. Así, en plena efusión de la venta de todo tipo de gracias, mercedes y plazas en el Perú, el arzobispo-virrey don Melchor de Liñán y Cisneros hubo de dar cuenta a la Corona de haber dictado una disposición para evitar que este mercado estuviese abierto a cualquiera. El prelado, en calidad de virrey, informó de la publicación en Lima una real cédula fechada el 17 de diciembre de 1679, por la que prohibía que cualquier deudor de la Real Hacienda pudiese ser elegido como alcalde ordinario o para otros oficios relacionados con la administración de la justica. Más aún, la mencionada disposición hizo énfasis en

\footnotetext{
${ }^{20}$ Sanz Tapia, ¿Corrupción o necesidad? La venta de cargos, 53.

${ }^{21}$ Ernst Schäfer, El Consejo Real y Supremo de las Indias. Su historia, organización y labor administrativa hasta la terminación de la casa de Austria (Sevilla: Imp. M. Carmona, 1935), 284.

${ }^{22}$ Domingo Marcos Giménez Carrillo, "La venta de hábitos de las órdenes militares en el siglo XVII. Entre la ocultación y el delito de simonía”, en El poder del dinero. Ventas de cargos y honores en el Antiguo Régimen, eds. Francisco Andújar Castillo y María del Mar Felices de la Fuente (Madrid: Biblioteca Nueva, 2011), 310 .
} 
prohibir el acceso a estos cargos a aquellos que acumularon débitos con el Fisco en razón a "la compra de oficios [...], deudas de alcabalas y otros ramos de Hacienda"23.

Pero las limitaciones señaladas -en las que no se menciona si las deudas por compras de títulos fueron también obstáculos- tuvieron una corta vigencia. Algo más de un año después de la comunicación del mitrado, el nuevo virrey, el duque de la Palata, indicaba que había puesto en marcha lo ordenado en el real despacho del 29 de junio de 1681. Esta disposición vino a mandar que se beneficiasen todos los oficios reales posibles dentro del distrito de la Audiencia de Lima y del resto de Chancillerías sufragáneas del Virreinato. Palata puso en marcha la medida, pero se mostró contrario a la misma a pesar del ingreso prometido a la Real Hacienda. Para don Melchor de Navarra y Rocafull lo más idóneo hubiese sido buscar para la administración “sujetos capaces y de la seguridad que conviene para el ejercicio de estos oficios y, si no se hallaren tales, no se rematarán aunque salga bien la cuenta" ${ }^{24}$. A la misma vez, pero en otra carta, Palata notificó haber aplicado otro real despacho, este del 17 de junio de 1681, por el que los oficios vendibles y renunciables, las gracias y mercedes, no fuesen dados nunca más en alquiler y que si se ejercían de forma interina fuese sólo para no entorpecer el funcionamiento de la administración $^{25}$. No obstante, estas medidas no dieron el fruto deseado. La venalidad no alcanzó las cotas deseadas desde la Península Ibérica y en 1690 se volvió a hacer hincapié en que se enajenase cuanto se pudiese. Así, en 1692 el virrey conde de la Monclova hubo de despachar noticia a la Corte de que había vuelto a poner en venta todos aquellos oficios posibles de la Audiencia de Lima, los cuales ya fueron dictados por Palata ${ }^{26}$. En cualquier caso, la urgencia de la Corona por obtener ingresos a través de la venalidad no fue siempre paralela a su materialización, pues en muchos casos los pagos se demoraron e incluso se suspendieron. Así, están constatados casos en los que la venta de títulos nobiliarios no fue correspondida con la pecunia a favor del Erario Regio por el simple motivo de que los beneficiados no disponían de las cantidades comprometidas. Por ello, existieron títulos enajenados que no llegaron a expedirse o que acumularon desde su creación deudas elevadas, hasta el grado de solicitar a la Corte aplazamientos en sus obligaciones ${ }^{27}$.

\footnotetext{
${ }^{23}$ Archivo General de Indias (en adelante AGI), Lima, 81, Carta del arzobispo-virrey Melchor de Liñán y Cisneros al Rey, Lima, 6 de agosto de 1681.

${ }^{24}$ AGI, Lima, 82, Carta del virrey duque de la Palata al Rey, Lima, 30 de noviembre de 1682.

${ }^{25}$ AGI, Lima, 82, Carta del virrey duque de la Palata al Rey, Lima, 30 de noviembre de 1682.

${ }^{26}$ AGI, Lima, 89, Carta del conde de la Monclova al Rey, Lima, 5 de agosto de 1692.

${ }^{27}$ Felices de la Fuente, "Recompensar servicios con honores", 413.
} 
Con mayor o menor volumen de enajenaciones, lo cierto es que el ingreso favorable a la Real Hacienda no era equiparable al daño sustanciable que la venalidad exacerbada produjo en la administración y en la sociedad indiana. De un lado, la eficacia y el prestigio propio de los órganos de gobierno se vio resentido y, de otra parte, aquellos que habían desembolsado una cantidad en la almoneda agraviaron a aquellos beneméritos y personas capacitadas para el ejercicio de los diversos cargos y mercedes ${ }^{28}$. Además, por si no fuesen estos daños cuantiosos, debemos tener en cuenta que los sujetos compradores esperaban un retorno pecuniario de la inversión realizada, favoreciendo de esta manera el desarrollo de prácticas ilegales. No obstante, parece ser que el interés económico del Fisco fue superior a cualquier tipo de reparo. Así, los beneficios obtenidos por la venta de cargos pesaron mucho a la hora de determinar la política desde la Corte, pero, tal y como ocurre a la hora de cuantificar los títulos, la disparidad historiográfica no termina de resolver por cuánto dinero se venció la balanza hacia una decisión -la de enajenar sólo en beneméritos y personas de solvencia reconocida- o hacia otra - poner los puestos en almoneda al mejor postor-. De esta manera, el "motivo" esgrimido en el Consejo de Indias variará entre los 678.800 pesos fruto de la venalidad en Perú entre 1674 y $1700^{29}$; los 600.000 pesos, aproximadamente, si nos centramos en el período de 1687 a 1712 para el mismo Virreinato ${ }^{30}$; o, si tenemos en cuenta el global de los dominios hispanos en las Indias, un total de 6.604 .857 pesos entre 1651 y $1700^{31}$. En cualquier caso, independientemente de las cifras que tomemos, a estas cantidades hay que añadir el dinero resultante de la venta de hábitos y títulos nobiliarios.

Sin embargo, podemos hallar otra diferencia, para ahondar en separadores, entre los compradores de "trabajos" y aquellos que adquieren gracias y mercedes. Los que consiguieron una plaza emplearon su permanencia en ella, en el caso de Lima, para crear y sostener una amplia red de contactos a nivel político, social y económico con la que sostener su posición. Estas estructuras clientelares llegaron a tal extremo que los provistos, en los casos más exitosos de carreras indianas, no desearon ascensos u otros cargos fuera de la Ciudad de los Reyes, puesto que en ella ya habían construido un

\footnotetext{
${ }^{28}$ Sanz Tapia, ¿Corrupción o necesidad? La venta de cargos, 54.

${ }^{29}$ Sanz Tapia, ¿Corrupción o necesidad? La venta de cargos, 54.

${ }^{30}$ Mark Burkholder y D.S. Chandler, De la impotencia a la autoridad. La Corona española y las Audiencias en América, 1687-1808 (México: Fondo de Cultura Económica, 1984), 36.

31 Ángel Sanz Tapia, "El proceso de venta y beneficio de cargos indianos en el siglo XVII", en La venta de cargos y el ejercicio del poder en Indias, coords. Julián Bautista Ruiz Rivera y Ángel Sanz Tapia (León: Universidad de León, 2007), 53.
} 
andamiaje lo suficientemente estable y rentable como para abandonarlo ${ }^{32}$. Por su parte, los individuos que habían obtenido una merced de hábito o la gracia de un título nobiliario no sólo experimentaron un ascenso social, sino que además pasaron a poseer un "bien mueble" que no dependió de una red clientelar en una parte u otra del Virreinato. La validez del título conseguido en la almoneda se extendía por toda la Monarquía. No obstante, lo que sí permitió la venalidad tan exacerbada en este período fue el aumento de los criollos en la administración y en la cúspide estamental ${ }^{33}$. Así, de esta manera, familias determinadas llegaron a convertirse en clanes cabeceros del Perú, refrendando desde diferentes posiciones funcionariales su estatus privilegiado al conseguir el ansiado título nobiliario.

Pero si hubo algo que terminó por separar en el mercado venal los oficios de las mercedes de privilegio, eso fue el reporte de prestigio. Si poseer una plaza en la administración ya supuso un reconocimiento de un amplio grado -aunque en un espectro variado en razón al oficio-, el título nobiliario situaba a su poseedor en la cúspide de la sociedad colonial. Bien es cierto que el empleo real daba al sujeto un papel importante en el espacio indiano, pues por sus manos pasaba parte del gobierno e incluso, en algunas jurisdicciones, casi su totalidad ${ }^{34}$, pero, en nuestra opinión, el prestigio conseguido a través de la titulación tuvo poco parangón. En cualquier caso, no debemos olvidar nunca la perspectiva de que el sujeto que acudía a la almoneda no lo hacía por cuestiones meramente sociales. La inmensa mayoría esperaba, tras satisfacer lo demandado por la Real Hacienda, un retorno de capital por vías legales o ilegales. Así, es conocido que los precios estipulados por la Corona para la venta de oficios nunca estuvieron relacionados con las ganancias previstas a través del sueldo señalado para cada empleo, por lo que el camino para esa vuelta de capital no quedó más remedio que corresponder con el ilícito ${ }^{35}$.

En una sociedad colonial, estamental y con reglas de comportamiento muy marcado, el honor, adquirido, conservado o heredado, se antoja fundamental para comprender a los sujetos que se aprovechan de la venalidad. Esto es algo que se explica

\footnotetext{
${ }^{32}$ Kenneth J. Andrien, Crisis y decadencia. El virreinato del Perú en el siglo XVII (Lima: Banco Central de la Reserva de Perú e Instituto de Estudios Peruanos, 2011), 154.

${ }^{33}$ Burkholder y Chandler, De la impotencia a la autoridad, 33.

34 Ángel Sanz Tapia, "La venta de oficios de hacienda en la Audiencia de Quito (1650-1700)", Revista de Indias, no LXIII (2003): 646.

${ }^{35}$ Horst Pietschmann, "Burocracia y corrupción en Hispanoamérica colonial. Una aproximación tentativa", Nova americana, $\mathrm{n}^{\circ} 5$ (1982): 24.
} 
por la distancia existente entre los súbditos americanos y el Rey. Así, ante la lejanía de la Corona, la posesión del "honor reconocido" se convirtió en arma indiscutible para la resolución de conflictos, públicos y privados, y otros de carácter socio-políticos ${ }^{36}$. En este sentido y con este valor, muchos no dudaron en acudir al mercado venal para hacerse con la propiedad de un título nobiliario, pues ello suponía un reconocimiento indudable y el salto hacia una nueva posición de partida mucho más elevada ante cualquier contingencia política, económica o social. Sin embargo, el acceso a este nuevo escalón siempre se vio empañado si el método para subir a él estaba manchado por el dinero. Así, como hemos apuntado, algunas enajenaciones fueron maquilladas con nombres como el de "donativos voluntarios", ocultando lo que en realidad no fue otra cosa que una transacción ${ }^{37}$. Un ejemplo de ello, en la Península Ibérica, fue el caso de compra protagonizado por Juan Arias de Saavedra al adquirir, entre operaciones de disimulo, el marquesado del Moscoso en $1680^{38}$.

Un mercado enorme, el de la venta de oficios, gracias y mercedes, que originó numerosos ingresos para la Real Hacienda, pero también múltiples vías y mecanismos para satisfacer a la otra parte interesada en las enajenaciones. Algunos de éstos fueron considerados ilegales y prohibidos nada más detectarse su existencia; uno de ellos fue el de la reventa. A esta práctica se acachó el problema de la rebaja de calidades entre los ocupantes de los diferentes oficios, cargos y plazas, pues las provisiones eran traspasadas por sus beneficiarios en busca de réditos económicos, alcanzando tal grado que la gracia regia se convirtió en mercancía de público intercambio. Así, un real decreto del 14 de mayo de 1705 fue dictado con la intención de corregir la reventa, obligando a las autoridades virreinales a no permitir este tipo de $\operatorname{traspasos}^{39}$. Por razones obvias, de este mercado "de segunda mano" escaparon, en cierto modo, títulos nobiliarios y hábitos de órdenes militares. Pero no lo hicieron del todo, pues concesiones con facultad de ser materializadas en terceras personas provocaron que se creasen almonedas particulares. En este sentido cabe destacar que la enajenación de títulos a través de instituciones

\footnotetext{
${ }^{36}$ Pilar Latasa Vassallo, "La corte virreinal peruana: perspectivas de análisis (siglos XVI y XVII)", en $E l$ gobierno de un mundo: virreinatos y audiencias en la América hispánica, coord. Feliciano Barrios Pintado (Cuenca: Universidad de Castilla La Mancha, 2004), 354-355.

${ }^{37}$ Antonio Domínguez Ortiz, Política y hacienda de Felipe IV (Madrid: ed. Derecho Financiero, 1960), 303.

${ }^{38}$ Ismael Jiménez Jiménez, "Nacimiento y primeros pasos de un nuevo título de Castilla: el marquesado del Moscoso", en El cardenal Portocarrero y su tiempo (1635-1709). Biografias estelares y procesos influyentes, coord. José Manuel de Bernardo Ares (Córdoba: CSED Historia, 2013), 161.

${ }_{39}$ Alfredo Moreno Cebrián, "Venta y beneficios de los corregimientos peruanos", Revista de Indias XXXVI, (1976): 225.
} 
eclesiásticas se hizo muy común desde finales del siglo XVII, pues adquirirlos de esta forma sólo requería la entrega del capital ${ }^{40}$.

Independientemente de los costes originados para la sociedad indiana, la administración colonial y los beneficios individuales, los ingresos materializados por la Real Hacienda, etc. lo cierto fue que grandes partidas de capital pusieron rumbo a la Corte como contraprestación de cargos y mercedes. Aunque la tesis tradicional ha sido defender que estos ingresos extraordinarios fueron dedicados de inmediato a cubrir gastos militares y exteriores de la Monarquía, nuevas líneas de investigación apuntan a otros destinos. Así, se ha comprobado cómo la cuenta de "gastos secretos" de la Corona, la "vía reservada" del Consejo de Hacienda o los gastos de la Cámara de Indias fueron nutridos por diversas vías, siendo una de sus principales fuentes de caudal la venta de cargos y honores radicados en las Indias y en Italia ${ }^{41}$.

\section{La compra de títulos nobiliarios en el Perú.}

Como hemos venido desarrollando a lo largo de estas páginas, el ascenso social fue aspiración prioritaria para muchos súbditos de la Monarquía, inclusive, claro está, el Virreinato del Perú. Así, el reconocimiento social por medio del ennoblecimiento fue un anhelo de muchos, máxime cuando de un título se trataba. Un título supuso el disfrute de una notabilidad social importante, ofreciendo al titulado nuevas relaciones ventajosas en el plano clientelar y económico, entretejiendo lazos entre las élites indianas y la Corona que tuvieron mucho que ver con las necesidades económicas de ésta última ${ }^{42}$. No obstante, para el acceso a este escalón de la nobleza se necesitaron una serie de requisitos preestablecidos, principalmente la consecución de la gracia regia, ya sea mediante la validación de méritos o bien a través del servicio económico, opción mayoritaria. Además de ello, para disfrutar de un título, se demandaron otras cuestiones como la posesión de caudales suficientes como para mantener públicamente la posición -lo que incluía la exhibición de símbolos y prácticas propias del estamento-, el pago de tributos especiales para la nobleza, como el impuesto de lanzas, y la satisfacción de la media annata tras

\footnotetext{
${ }^{40}$ Felices de la Fuente, "Silencio y ocultaciones", 234.

${ }^{41}$ Francisco Andújar Castillo, "Gastos secretos y venalidad en el siglo XVII", en Herederas de Clío. Mujeres que han impulsado la Historia, eds. Gloria Franco Rubio y María Ángeles Pérez Samper (Sevilla: Mergablum, 2014), 38-39.

${ }^{42}$ Maruri Villanueva, "Poder con poder se paga", 231-232.
} 
haber obtenido el título ${ }^{43}$. En este sentido, la Corona satisfacía a los interesados en el ennoblecimiento máximo y, gracias a la venalidad y a otras medidas fiscales, se beneficiaba económicamente de forma directa. Por ello mismo y por las necesidades fiscales, desde que se abrió definitivamente la veda a la enajenación de títulos en el primer tercio del siglo XVII, se hizo hincapié en recaudar las cantidades íntegras y en el menor tiempo posible. Así, el conde-duque de Olivares, tras obtener de Felipe IV la aprobación para la creación del tributo de lanzas, insistió sobremanera en exigir su pago a la nobleza ya titulada e incluso gravar con el mismo a los "nuevos nobles" como conjunto indivisible de la media annata en su primer año en tal condición privilegiada ${ }^{44}$.

Esta política por parte de la Corona produjo un efecto secundario al aumento de la recaudación hacendística y al de la nobleza titulada. Desde mediados del Seiscientos se comprobó cómo los nuevos títulos pasaron a ser entregados a cambio de servicios, trastocando el sistema tradicional de recompensas en el estamento privilegiado, es decir, se pasó de reconocer los méritos propios y heredados a considerar principalmente las prestaciones realizadas en favor de la Monarquía, esencialmente aquellas de carácter pecuniario. Por esta razón, desde la Corte se observó que las Indias podían rentar grandes beneficios venales que aliviasen al Fisco Regio y satisficiesen las demandas de los más acaudalados americanos. Así, la enajenación de títulos se convirtió en una fuente de ingresos importantes, facilitando la respuesta ante gastos extraordinarios y relajando otras demandas presupuestarias ${ }^{45}$.

En este sentido, buscando aumentar los haberes de la Real Hacienda, se reglamentó por real cédula del 30 de agosto de 1692 que todos los títulos que se hubiesen beneficiado desde el primero de 1689 por una cantidad inferior a los 30.000 ducados tuviesen la consideración de vitalicios, a no ser que el titulado reintegrase la cantidad faltante hasta la citada para obtener el título en calidad de perpetuo. No obstante, el éxito de la medida no debió ser muy notable para el Fisco, amén de las quejas de los "titulados vitalicios", puesto que una nueva real cédula del 18 de abril de 1695 bajó la condición perpetua a los 22.000 ducados $^{46}$.

\footnotetext{
${ }^{43}$ Andújar Castillo, "Hacerse noble a finales del siglo XVII", 17-18.

${ }^{44}$ Felices de la Fuente, "Recompensar servicios con honores", 413.

45 Andújar Castillo, "Gastos secretos y venalidad", 42.

${ }^{46}$ Maruri Villanueva, "Poder con poder se paga", 216.
} 
La institución encargada de recaudar estos capitales procedentes de la venta de títulos nobiliarios en suelo americano fue la Cámara de Indias, donde se registraron los nuevos títulos con solar indiano. No obstante, que la Cámara americana ejerciese estas competencias fue siempre fruto de controversias con la Cámara de Castilla, pues ésta última entendía que esa actividad le restaba parte de sus obligaciones y poder, pues no era informada de forma jerárquica por su homóloga para América ${ }^{47}$. En cualquier caso, desde el reinado de Felipe IV el aumento de la nobleza titulada comenzó a ser palpable, alcanzando los mayores números bajo Carlos II, provocando el fenómeno conocido como inflación de honores ${ }^{48}$. No obstante, este crecimiento de títulos continuó hasta el fin de la presencia española en las Indias, lo cual dejó un total de noventa títulos beneficiados entre 1681 y $1821^{49}$. Un hecho que estuvo vinculado, sin duda alguna, a la labor protagonizada por la Cámara de Indias.

La puesta en almoneda de títulos nobiliarios tuvo una fecha clave: 1679. Ese año no fueron las necesidades de la Real Hacienda las que hicieron que la Cámara de Indias fuese receptiva a las ofertas para títulos realizadas por, en nuestro caso, criollos peruanos; los cuales fueron los más activos a la hora de adquirir éstos ${ }^{50}$. Por primera vez en el siglo XVII, la guerra no requirió de ingresos de origen venal ${ }^{51}$. Así pues, en 1679 se ofertaron numerosos títulos para aquellos con capitales suficientes, pues apremiaban las necesidades financieras para el casamiento de Carlos II con María Luisa de Orleans. El Fisco Regio no contaba con fondos como para soportar este elevado gasto extraordinario $\mathrm{y}$, aprovechando el contexto señalado de la inflación de honores, dispuso la venta de al menos treinta y cinco títulos. Para acudir a esta almoneda, dadas las exigencias perentorias, se relajaron los requisitos hasta el punto de que algunos sujetos de los que presentaron ofertas tuvieron un dudoso origen ${ }^{52}$. La única cláusula que se puso para pujar por estos títulos fue la posesión del capital suficiente, pues se había estipulado que se enajenasen por 30.000 ducados cada uno.

La reacción fue inmediata en la Península Ibérica y a esta almoneda acudieron nobles, especialmente segundones - como fue el caso de Juan Arias de Saavedra, quien a

\footnotetext{
${ }^{47}$ Felices de la Fuente, "Recompensar servicios con honores", 415.

${ }^{48}$ Felices de la Fuente, "Recompensar servicios con honores", 411.

${ }^{49}$ Maruri Villanueva, "Poder con poder se paga", 209.

${ }^{50}$ Maruri Villanueva, "Poder con poder se paga", 219.

${ }^{51}$ Rodríguez Hernández, "La creación de títulos”, 186.

${ }^{52}$ Felices de la Fuente, "Recompensar servicios con honores", 416.
} 
partir de aquel año pasaría a ser marqués del $\operatorname{Moscoso}^{53}-$, y pecheros, principalmente comerciantes, con capitales suficientes. En las Indias, por efecto del factor tiempo ${ }^{54}$, la respuesta a esta venta "masiva" comenzó con la década de 1680. A partir de entonces no sólo se vendieron gracias y mercedes, sino que el caudal que por este concepto llegó a la Corte aumentó considerablemente, nutriendo, entre otros destinos, a la caja de gastos secretos gestionada por Juan Antonio Domínguez ${ }^{55}$. En cualquier caso, 1679 es la fecha en la que definitivamente se pasó de otorgar títulos por méritos, propios o familiares, a hacerlo a cambio de dinero. Un trastoque del mecanismo hasta entonces establecido a uno y otro lado del Atlántico - "servir para ser recompensado y de recompensar para obtener más servicios" ${ } 56$-, que desembocó en un aumento más que considerable de la nobleza titulada. Esto, a su vez, desarmó parte de la exclusividad del estamento privilegiado, pues permitió la entrada de sujetos con orígenes diversos y, en un cercano tiempo atrás, hasta excluidos de cualquier atisbo de pertenecer a este grupo ${ }^{57}$.

En Perú estas ventas tuvieron lugar bajo el virreinato de don Melchor de Navarra y Rocafull, duque de la Palata. Este virrey, que permaneció en Lima entre 1681 y 1689, fue el encargado de recibir la petición de enajenar once "títulos de Castilla" por orden de la Cámara de Indias para sufragar los gastos comprometidos por el casamiento del monarca en 1679. Fue el propio Palata quien, en el memorial ajustado sobre su juicio de residencia en 1690, declaró que había beneficiado once títulos, a razón de 30.000 pesos de a ocho reales cada uno de ellos ${ }^{58}$. Sin embargo, los 330.000 pesos obtenidos, no fueron ingresados en la Real Hacienda al contado y en un solo pago, como fue deseo de la Corte, sino que la enajenación de estos títulos llevó un ritmo particular y muy diverso entre sín ${ }^{59}$.

Sabemos que el primer peruano en adquirir uno de estos títulos fue Luis Ibáñez de Segovia Peralta, quien en 1681 compró el marquesado de Corpa para él y el condado de Torreblanca para su hijo, Luis Ibáñez de Segovia y Orellana, a cambio de 60.000 pesos $^{60}$. Posteriormente, tenemos noticia de otro comprador por una carta del virrey Palata a

\footnotetext{
53 Jiménez Jiménez, "Nacimiento y primeros pasos de un nuevo título de Castilla”, 161.

${ }^{54}$ Ramón María Serrera Contreras, "Geografía y poder en el siglo XVII indiano: el factor distancia en el incumplimiento de la norma", en Libro homenaje "in memoriam" Carlos Díaz Rementería, VV.AA. (Huelva: Secretariado de Publicaciones de la Universidad de Huelva, 1998), 691-699.

55 Andújar Castillo, "Gastos secretos y venalidad", 39.

${ }^{56}$ Felices de la Fuente, "Silencio y ocultaciones", 230.

${ }^{57}$ Felices de la Fuente, "Recompensar servicios con honores", 416.

${ }^{58}$ Lewis Hanke y Celso Rodríguez, Los virreyes españoles en América durante el gobierno de la casa de Austria, Perú, vol. VII (Madrid: Atlas, 1980), 86.

${ }^{59}$ AGI, Lima, 87, Memorial ajustado de la residencia del duque de la Palata, s.1., 1690.

${ }^{60}$ Maruri Villanueva, "Poder con poder se paga", 220.
} 
Carlos II fechada en noviembre de 1683. En ella se hace saber que la almoneda de estos títulos no se realizó de una sola vez: primero se vendió un lote de cuatro títulos, pues así quedó dispuesto en una real cédula fechada el 23 de febrero de 1683. Por este documento se estimó que se entregasen los títulos a cambio de un servicio pecuniario y el pago de la media annata, sin tener en cuenta otros méritos. Así, Francisco de la Cueva y Guzmán, caballero de la orden de Alcántara y maestre de campo del tercio del batallón de Lima, compró un título tras acordar el ingreso efectivo e inmediato de 20.000 pesos en la Caja Real de Lima y prometer los restantes 10.000 en la siguiente armada -la cual tuvo lugar dos años después-. Según este acuerdo, Cueva y Guzmán sólo obtendría la titulación cuando, tras completar los pagos, satisficiese la media annata; a partir de ese momento podría ostentar el marquesado de Santa Lucía de Cochán, hacienda de su propiedad cercana a Charcas ${ }^{61}$.

Dos años después de esta primera venta, Palata escribió a la Corona dando buena cuenta de haber completado la enajenación de los cuatro títulos dispuestos en la real cédula citada. En este caso los beneficiados fueron, los citados, Luis Ibáñez de Segovia Peralta y su hijo Luis Ybáñez de Segovia Orellana, Diego de Vargas Carvaxal y Luis de Oviedo y Herrera. Además, informaba de la negativa que se le había dado a Francisco de la Cueva y Guzmán de obtener jurisdicción señorial sobre el marquesado que compró, manteniéndosele el título pero no otorgándoseles estas preeminencias. En esta nueva misiva el virrey no se limitó a confirmar el cumplimiento de las órdenes recibidas desde la Península Ibérica, sino que mostró iniciativa propia y solicitó que se confirmasen almonedas que él mismo había dispuesto. Palata había vendido cuatro títulos nobiliarios más por 30.000 pesos cada uno, a pagar en dos veces: 20.000 al contado y lo restante el día que se concediese la merced y se mostrase el recibo de haber satisfecho la media annata. Así pues, don Melchor de Navarra pidió que se confirmasen las operaciones del marquesado de Valleumbroso para Diego de Esquivel y Xarava, del condado de la Laguna para Pedro de Peralta y de los Ríos, del condado de Cartago para José Hurtado de Chaves y del condado de la Vega del Ren para Josefa Zorrilla de la Gándara ${ }^{62}$.

\footnotetext{
${ }^{61}$ AGI, Lima, 83, Carta del virrey duque de la Palata al Rey informando de la enajenación del marquesado de Santa Lucía de Cochán, Lima, 13 de noviembre de 1683.

${ }^{62}$ AGI, Lima, 84, Carta del virrey duque de la Palata al Rey sobre la enajenación y confirmación de títulos, Lima, 4 de abril de 1685 .
} 
Pero no todos estos títulos enajenados fueron otorgados de manera inmediata y con la sencillez que indican los plazos de pago acordados. Años después de que José Hurtado de Chaves fuese nombrado conde de Cartago aún esperaba la confirmación del título. El conde in pectore denunciaba que había entregado en forma y manera los 30.000 pesos a la Real Hacienda y que éstos fueron inmediatamente destinados a sufragar las renovadas fortificaciones de Portobelo, pero por no disponer de capitales suficientes no había obtenido la referida confirmación. Sin embargo, según narra Hurtado de Chaves, otros titulados recientes como el conde de Castillejo o el marqués de Corpa, sí consiguieron la confirmación mediante acuerdos de aplazamiento. Por ello y por haber servido con su dinero y con puntualidad a la Corona, demandaba que se le confirmase con carácter hereditario el condado de Cartago; petición aprobada por el Consejo en diciembre de $1686^{63}$. No se había cumplido un año desde que se aceptaron estas demandas cuando José Hurtado de Chaves falleció, legando el título comprado en su hijo, Baltasar Hurtado de Chaves y Quesada. El segundo conde de Cartago no se contentó con su pertenencia a la nobleza titulada, sino que, usando el mismo mecanismo venal que su padre, pretendió ampliar este estatus con un hábito de orden militar. Así, empleando como intermediario al virrey Palata, demandó su nombramiento como caballero. Para ello argumentó tanto méritos como servicios, es decir, su embarque en la Armada del Mar del Sur durante dieciocho meses en 1685 para luchar contra los piratas, su empleo como alférez y el coste asumido de formar una compañía de cien hombres con dos pagas satisfechas ${ }^{64}$. Razón, esta última, que fue la verdadera para que se le concediese el hábito de Santiago 65 .

Estos problemas de confirmación no fueron los únicos a los que hubo de enfrentarse Palata tras la almoneda de los once títulos. Derivados de estas operaciones aparecieron otras trabas relacionadas con la fiscalidad anexa a los nuevos titulados. Así, aunque el virrey cumplió con aplicar todo lo recaudado con las ventas a la defensa del Mar del Sur -ya no era necesario contribuir al desposorio regio, según puede deducirse, los nuevos impuestos establecidos a la nobleza causaron contratiempos. El servicio de lanzas, ideado por el conde-duque de Olivares en 1631 para la contribución de los nobles

\footnotetext{
63 AGI, Lima, 174, Aprobación del Consejo y Cámara de Indias de la confirmación del condado de Cartago, Madrid, 2 de diciembre de 1686.

${ }^{64}$ AGI, Lima, 86, Carta del virrey duque de la Palata al Rey en favor de la pretensión del conde de Cartago de un hábito, Lima, 7 de octubre de 1687.

${ }^{65}$ Guillermo Lohmann Villena, Los americanos en las órdenes nobiliarias, t. I (Madrid: Consejo Superior de Investigaciones Científicas, 1993), 87.
} 
a los gastos militares, tuvo una difícil aplicación en Perú aún más de medio siglo después de su creación. Palata fue consciente del problema y así lo hizo constar cuando expresó que las lanzas "es materia que aquí parecerá muy nueva, porque de los pocos títulos antiguos que había nunca se han cobrado, ni yo sabré en qué forma ni en qué cantidad las han de pagar". Es decir, aunque por real despacho de 3 de mayo de 1688 se le conminó a recaudar dicho tributo en los nuevos nobles, ni el virrey ni el Real Acuerdo sabían cómo y cuánto debían recaudar. Por ello, Palata solicitó que se le enviase el derecho sobre el que habría de cobrar esta contribución, haciendo especial hincapié en si sólo tenía que ser aplicado en aquellos que tenían vasallos a su cargo, pues de ser así el marqués de Oropesa sería el único en pagar las lanzas ${ }^{66}$.

En cualquier caso, pese a las complicaciones inherentes a operaciones de tal calibre como la venta de títulos nobiliarios, durante el gobierno del duque de la Palata se habían ingresado en la Real Hacienda por este concepto 330.000 pesos. Sin embargo, por la cantidad indefinida en tributos anexos a estas almonedas, al virrey se le exigieron explicaciones sobre estas cuestiones en su juicio de residencia. La respuesta de Palata no fue otra que manifestar que "no sabe cómo se le pide cuenta de Hacienda Real a un virrey teniendo su Majestad oficiales reales que deben darla, porque entra en su poder" y además exhibió los ingresos $\operatorname{citados}^{67}$. A pesar de esta cuestión, podemos señalar que durante los ocho años de gobierno de don Melchor de Navarra se enajenaron los siguientes títulos en el Virreinato de Perú:

Títulos Vendidos en Perú entre 1681 y 1689.

\begin{tabular}{c|c}
\hline TÍTUlO & BENEFICIADO \\
\hline Conde de Cartago & José Hurtado de Chaves \\
\hline Conde de Castillejo & Diego de Vargas Carvaxal \\
\hline Conde de la Granja & Luis de Oviedo y Herrera \\
\hline Conde de la Laguna & Pedro Peralta y de los Ríos \\
\hline Conde de la Vega Ren & Josefa Zorrilla de la Gándara \\
\hline Conde de Santa Ana de las Torres & Nicolás Dávalos y Ribera \\
\hline Conde de Torreblanca & Luis Ybáñez de Segovia Orellana \\
\hline Marqués de Corpa & Luis Ybáñez de Segovia Peralta \\
\hline Marqués de Monterrico & Melchor Malo de Molina \\
\hline Marqués de Santa Lucía de Cochán & Francisco de la Cueva y Guzmán
\end{tabular}

\footnotetext{
${ }^{66}$ AGI, Lima, 88, Carta del virrey duque de la Palata al Rey sobre el derecho de lanzas a aplicar en Perú, Lima, 18 de enero de 1689.

${ }^{67}$ AGI, Escribanía de Cámara, 543 A, Respuesta del virrey duque de la Palata al auto del 5 de octubre de 1689 sobre títulos beneficiados en su juicio de residencia, Lima, 17 de octubre de 1689.
} 
La sustitución de don Melchor de Navarra en el Palacio virreinal de Lima no significó el fin de la venta de títulos nobiliarios en Perú. Durante el gobierno de don Melchor Portocarrero, conde de la Monclova, estas almonedas continuaron vigentes. Muestra de ello fue el caso de Tomás González Galeano. Comerciante y hacendado, este limeño obtuvo en 1696 el título de marqués de Sotoflorido, demostrando nuevamente que la posesión de capital se había convertido en el camino más sencillo para acceder a la nobleza titulada. Sin embargo, la consecución de este marquesado no fue sencilla, ni barata, para González Galeano. Como bien estudió el profesor Andújar Castillo, este criollo comenzó a gestionar su intitulación en marzo de 1692, pues fue entonces cuando depositó en la tesorería del Consejo de Indias 17.000 pesos como complemento a los méritos de su progenitor, el capitán Francisco González Galeano, para conseguir la propiedad del oficio de pagador general de la gente de mar y guerra del presidio del Callao.

Cuatro años después, González Galeano volvió a acudir a la almoneda para obtener el marquesado, añadiendo en sus informes su labor en la rada chalaca. En esta ocasión, por la inflación de honores, los títulos habían elevado su precio hasta los 242.000 reales -cantidad establecida en marzo de 1693- si el comprador deseaba disfrutar del mismo con carácter hereditario. Sin embargo, resultó que González Galeano sólo pagó por su título 100.000 reales, el equivalente a 12.500 pesos de a ocho; una diferencia que ni el citado profesor Andújar, ni nosotros, puede explicar y que quizás pudo ser debida a una suerte de complemento por lo satisfecho en un oficio anterior. En cualquier caso, el dinero de González Galeano y sus ansias de reconocimiento no quedaron agotados. En 1697 volvió a la almoneda para hacerse con el corregimiento de Huamalíes a cambio de 4.000 pesos, aunque en esta ocasión es probable que el fin del cargo fuese su traspaso a un tercero ${ }^{68}$.

No fue este el único caso de compra de títulos en las postrimerías del siglo XVII y los inicios de la siguiente centuria bajo el virreinato del conde de la Monclova. En 1694 se concedió el condado de Sierrabella a Diego Cristóbal Messía, presidente de la Audiencia de Charcas y antiguo oidor de Lima, quien poco antes de fallecer lo legó a su primogénito, Diego Cristóbal Messía y Valenzuela. El magistrado consiguió la merced

\footnotetext{
${ }^{68}$ Andújar Castillo, "Hacerse noble a finales del siglo XVII", 27-29.
} 
del condado tras ofrecer una cuantiosa donación a favor de la Corona. El togado propuso que condonaría una encomienda que gozaba y que le rentaba la nada despreciable cifra de 2.000 ducados anuales, si se le concedía un título nobiliario hereditario. La generosa oferta fue aprobada en la Corte y el 12 de marzo de 1699 se expidió un real despacho ordenando al virrey conde de la Monclova que recogiese de Messía y Valenzuela las cédulas de la encomienda trocada, pues se temió que pudiesen seguir obteniendo réditos de ella. Un par de años después, Monclova notificó haber cumplido con la orden recibida, haciendo constar que la transacción acordada con el difunto Diego Cristóbal Messía se había completado: la Real Hacienda contaba con un nuevo ingreso y el magistrado había dejado un título a su primogénito ${ }^{69}$.

A pesar de la apariencia de conciliación y de trato amistoso de compra-venta, el conde de Sierrabella mandó una misiva de su padre aludiendo a las razones que tenía para conservar la jugosa encomienda. En este documento, Diego Cristóbal Messía exponía que se consideraba merecedor de la encomienda y del título nobiliario por sus servicios a la Corona en Indias, pero también por ser nieto de un conquistador del Perú y caballero veinticuatro de Sevilla, Diego Messía, y a su vez hijo de Cristóbal Messía, quien fue corregidor de Écija y de Ávila. Para el presidente de Charcas eran razones justificadas para mantener título y encomienda, compartiéndolas Messía y Valenzuela al adjuntar el documento $^{70}$.

No fueron las únicas reclamaciones hechas por sujetos que se habían intitulado gracias a la almoneda. Alrededor de 1700 el conde de Villanueva del Soto, García de Híjar y Mendoza solicitó a la Corona que se le devolviesen los 22.000 pesos de a diez reales de plata con los que el virrey conde de la Monclova lo había hecho servir a cambio de poder "gozar perpetuo" su nuevo título. El virrey recaudó este dinero tras recibir la real cédula de 11 de junio de 1695 que le ordenaba tomar la citada cantidad de todos aquellos que habían adquirido un título venalmente. Sin embargo, a pesar de entregar los caudales, Híjar y Mendoza alegó que había alcanzado el condado por sus méritos y no por ninguna contribución monetaria, razón por la cual deberían devolverle el montante. Además, Villanueva de Soto consideraba que ya servía generosamente a la Real

\footnotetext{
${ }^{69}$ AGI, Lima, 407, Carta del virrey conde de la Monclova al Rey sobre la devolución de la encomienda de Diego Cristóbal Messía, Lima, 26 de octubre de 1701.

${ }^{70}$ AGI, Lima, 407, Carta de Diego Cristóbal Messía al Rey, s.1., s.f.
} 
Hacienda: en aquel momento estaba presto a partir hacia Chile para ejercer la presidencia de su Audiencia, la cual había conseguido tras desembolsar en 1688 por una "futura" 10.500 pesos de a diez reales -pagados en dos plazos: 6.500 al contado y 4.000 tras tomar posesión-; además, anteriormente había comprado una contaduría del Tribunal de Cuentas de Lima para su hijo, García José de Híjar y Mendoza. Por estas contribuciones, el Consejo de Indias consideró que el conde de Villanueva de Soto había ayudado en los gastos de la Monarquía, exonerándolo del pago exigido por el virrey conde de la Monclova $^{71}$.

La resolución de esta reclamación destapó a los compradores peruanos de otros títulos nobiliarios durante la segunda mitad del siglo XVII. La decisión del Consejo sobre el conde de Villanueva de Soto fue recogida en una real cédula de 16 de noviembre 1703 que se le remitió a Monclova. Por ella, el virrey se comunicó con los sujetos que se consideraban exentos de contribuir con estos 22.000 pesos de a diez. Es decir, todos aquellos que habían obtenido su título en la almoneda y que aún lo mantenían con carácter vitalicio. Los señalados por el virrey fueron los siguientes: Gerónimo de Velasco y Castañeda, marqués de Villablanca, fallecido a la recepción de la real cédula y cuyo título había pasado a su hijo homónimo, quien se empleaba en Saña y presentó un despacho con la merced de perpetuidad concedida en fechas anteriores. Francisco Bravo de Sarabia, marqués de la Pica, quien servía a la Corona en Chile, había legado el título a su hija tras el fallecimiento de su esposa, Catalina de Iturrizarra, por lo que se consideraba libre de este tributo. Sin embargo, la nueva marquesa, Marcela Bravo de Sarabia, mostró su indisponibilidad para satisfacer los 22.000 pesos de a diez por haber liquidado sus capitales al pagar la media annata. Ante esta situación, el Real Acuerdo consideró que la marquesa de la Pica había mostrado verdadera intención de contribuir con lo demandado, razón por la cual le permitieron disfrutar del título de forma interina hasta conseguir el dinero suficiente para convertirlo en hereditario. Por último, el virrey dio a conocer el caso de Francisca de Soto y Baca, marquesa de Selvahermosa, la cual fue conminada a depositar el dinero sin éxito alguno ${ }^{72}$.

\footnotetext{
71 AGI, Lima, 344, Resolución del Consejo de Indias sobre la contribución solicitada al conde de Villanueva de Soto, Madrid, 10 de octubre de 1703.

72 AGI, Lima, 407, Carta del virrey conde de la Monclova al Rey sobre la contribución solicitada a los títulos enajenados, Lima, 20 de julio de 1704.
} 
En 1703 se enajenó el último de los títulos de los que haremos referencia y cuya excepcionalidad no radicó sólo en lo alargado de sus negociaciones, sino también en el sujeto que obtuvo la merced. En el citado año la Corona concedió a cambio de 140.000 pesos de oro el título de marqués de Villarrica de Salcedo al hijo de José Salcedo, cabecilla de los importantes disturbios acaecidos en Laicacota durante la década de $1660^{73}$. Unas revueltas que únicamente pudieron ser extirpadas por la marcha a la región del virrey conde de Lemos al mando de un ejército ${ }^{74}$. Habían pasado treinta y cinco años desde que Gaspar y José Salcedo hicieron su primera intentona de acceder al estamento privilegiado, pues en 1668 habían ofertado a la Cámara de Indias 70.000 pesos de a ocho por un título y dos hábitos. En aquel momento, se les negó el acceso a la nobleza esgrimiendo las alteraciones que estaban liderando en Puno y por ser considerados, especialmente Gaspar Salcedo, "hombres de menos calidad de lo que se requiere para dignidad de tanto honor". Años después, en 1674, Salcedo volvió a solicitar venalmente un marquesado, obteniendo un nuevo rechazo ${ }^{75}$. Las disputas acaecidas entre andaluces y vizcaínos aún pesaban en la conciencia de las autoridades metropolitanas más que el dinero puesto sobre la mesa. Casi treinta años después, esto había cambiado...

\section{Consideraciones finales.}

En la segunda mitad del siglo XVII y los inicios del XVIII se produjo una venalidad creciente, amparada y alentada tanto por los poderes metropolitanos como por los coloniales. Consecuencia de ello fue la extensión del mercado de oficios, gracias y mercedes hasta niveles no conocidos entonces. Este fenómeno se debió a dos cuestiones principales: en primer lugar, a los jugosos ingresos que las ventas ofrecían a la siempre exhausta Real Hacienda; unos caudales netos que eran demasiado tentadores como para ser rechazados. En segundo orden, podemos defender que la creación y mantenimiento de esta amplia almoneda estuvo basada en la idea de conservar en buen ánimo los territorios indianos. Parte de la población criolla estaba anhelante de incorporarse a la clase privilegiada y una buena forma de canalizar estas ansias, sin provocar descontentos, fue la de poner en disposición de aquellos que más capital poseían los honores y

\footnotetext{
${ }^{73}$ AGI, Indiferente, 499, Título de marqués de Villarrica de Salcedo en favor de José de Salcedo, Madrid, 13 de noviembre de 1703 .

${ }^{74}$ José Antonio del Busto Duthurburu, "Los virreyes: vida y obra", en Historia General del Perú, eds. Guillermo Lohmann Villena y José Antonio del Busto Duthurburu (Lima: ed. Brasa, 1994), 172.

${ }^{75}$ Jorge Basadre Grohmann, El conde de Lemos y su tiempo (Lima: ed. Huascarán, 1948), 84.
} 
reconocimientos propios de la nobleza. Así pues, la venalidad traspasó cualquier tipo de frontera, argumentando siempre esta transgresión con cuantiosos pesos. De esta manera, no resultó descabellado que se llegasen a presentar ante el Consejo y la Cámara de Indias ofertas para la compra del cargo de virrey del Perú e incluso se formalizarse con el conde de Cañete del Pinar. Con ello, aunque el conde nunca ocupó el asiento virreinal, quedaron superadas todas las barreras y se alcanzó el culmen de la venta de oficios y gracias.

Casi parejo a este traspase de lindes, se constata un notable incremento de la nobleza titulada a un lado y otro del Atlántico; lo cual tuvo mayor significado cuando, a partir de 1686, se ordenó vender todo aquello que fuese posible en Perú. Así, la venalidad se extendió por todos los estratos de la sociedad virreinal, no quedando ni un solo resquicio por explotar para beneficio de la Real Hacienda y satisfacción de los demandantes de oficios y reconocimientos públicos. Sin embargo, anterior a esta fecha, el real decreto de 29 de junio de 1681 ya había apuntado esta tendencia, pues en él se ordenaba que se pusiese en almoneda cualquier plaza existente, o por existir, en el distrito de la Audiencia de Lima.

La consecuencia de estas medidas no fue otra que el aumento de criollos en la cúspide administrativa y estamental del Perú. La riqueza se había convertido en el medio más rápido para que la Corona abriese las puertas a los indianos de reconocimientos y oficios. Sin embargo, no todo fueron facilidades para los demandantes. A pesar de que obtuvieron por su pecunia las plazas, hábitos o títulos, en la sociedad peruana de la segunda mitad del XVII tuvo mucho peso la consideración del honor. Por ello, la demostración pública de que este honor, adquirido o heredado, no era más que un reconocimiento de la Corona a los méritos del individuo siguió siendo clave y parte indisoluble del ascenso social. Así pues, esta amplia almoneda requirió de cierto disimulo, pues los compradores exigían que no se supiese "de pública voz y fama" que su oficio u honor no se debía a sus calidades, sino a su dinero. Estamos ante un paisaje donde el peculio se había convertido en el motor de la movilidad social.

Así, el máximo reconocimiento social, es decir, la intitulación nobiliaria, fue anhelada por muchos súbditos americanos de la Monarquía, pero alcanzado por los pocos que habían amasado una fortuna. Aún con ello, el afán por lograr un título siempre requirió de la consecución ineludible de la gracia real. Durante el Seiscientos, este favor se obtuvo mediante dos vías: la acumulación de méritos y servicios a la Corona o la 
entrega de una cantidad pecuniaria determinada. No obstante, conforme fue avanzando la centuria, la consecución de esta gracia fue inclinándose paulatinamente hacia el medio económico, suponiendo cada vez menos el factor meritocrático. El desequilibrio de estos caminos hacia el título nobiliario estuvo premeditado por la Corona, pues al disponer en pública almoneda condados, marquesados, baronías, etc. obtuvo dobles beneficios. Resultó que ofreciendo estas titulaciones la Monarquía ganó unas cantidades pecuniarias notables sin apenas esfuerzo y, además, contentó a aquellos peruanos que deseaban el ascenso social definitivo dentro del estamento privilegiado.

Pero no todo fueron beneficios en este mercadeo de títulos. Con esta almoneda se produjo una modificación sustancial del sistema de provisión de las titulaciones. Como hemos apuntado, los méritos dejaron de ser el valor fundamental para estas concesiones y los pesos ofrecidos a la Real Hacienda se alzaron como el argumento definitivo para ostentar un blasón. A este trastoque hay que añadir el mayor volumen de las fortunas criollas, las cuales podían satisfacer al Fisco con moneda de buena ley. De esta manera se produjo un aumento de la nobleza titulada en los virreinatos americanos, desembocando en el fenómeno de "la inflación de honores".

Títulos Vendidos duRANTE EL REINAdo de CARLOS II Y SUS VIRREYES EN PERÚ (1681-1705).

\begin{tabular}{c}
\hline Título \\
\hline Condado de Cartago \\
\hline Condado de Castillejo \\
\hline Condado de la Granja \\
\hline Condado de la Laguna \\
\hline Condado de la Vega Ren \\
\hline Condado de las Torres \\
\hline Condado de Sierrabella \\
\hline Condado de Torreblanca \\
\hline Condado de Villanueva del Soto \\
\hline Marquesado de Corpa \\
\hline Marquesado de la Pica \\
\hline Marquesado de Monterrico \\
\hline Marquesado de Santa Lucía de Cochán \\
\hline Marquesado de Selvahermosa \\
\hline Marquesado de Sotoflorido \\
\hline Marquesado de Valleumbroso
\end{tabular}


La fecha clave de todo ello fue el año de 1679. El matrimonio de Carlos II con María Luisa de Orleans provocó que la venalidad creciese como vía para sufragar el enlace. El efecto inmediato de esta almoneda dictada por la Corona fue el relajamiento de los requisitos “extra-monetarios" para adquirir los títulos, la estipulación de un precio fijo para los mismos -30.000 ducados- y el citado aumento de la nobleza titulada. Para el caso peruano, las consecuencias de estas ventas se dejaron notar durante el virreinato del duque de la Palata (1681-1689). Este virrey hubo de enajenar hasta once títulos por un valor total de 330.000 pesos. Sin embargo, no fue el único de los virreyes que se vio en situación de vender estos honores, pues bajo el conde de la Monclova, máximo dirigente peruano entre 1689 y 1705, también se produjeron este tipo de transacciones. Ambos virreyes compartieron compra-ventas, pero también los problemas que las mismas ocasionaron. La confirmación de los títulos vendidos, el fraccionamiento no acordado o incumplido de los pagos y la satisfacción, o no, de tributos especiales como la media annata o las lanzas fueron complicaciones derivadas de la venalidad que hubieron de resolver Palata y Monclova entre los nuevos marqueses y condes y el Consejo y Cámara de Indias.

Dificultades aparte, lo cierto fue que durante el reinado de Carlos II el Perú vivió una almoneda de honores desconocida hasta entonces. Se enajenaron sin reparo alguno, pero sin olvidar el disimulo requerido, tanto oficios como títulos nobiliarios, para satisfacción de los súbditos de la Corona en aquel Virreinato. Sin embargo, desde entonces, por el ansia de reconocimiento social de aquellos sujetos que acudieron al mercado venal, el sistema de concesión de honores quedó trastocado para el resto del periodo colonial. Así, desde la segunda mitad del XVII, el dinero se convirtió en el factor indispensable, en muchas ocasiones único, para el ennoblecimiento de cualquier peruano. El capital había sustituido al mérito.

\section{Fuentes:}

Archivo General de Indias, sec. Escribanía de Cámara, legajo 543 A.

Archivo General de Indias, sec. Indiferente General, legajo 499.

Archivo General de Indias, sec. Lima, legajos 81, 82, 83, 84, 86, 87, 88, 89, 174, 344, 407. 


\section{BIBLIOGRAFÍA.}

ANDRIEN, Kenneth J. Crisis y decadencia. El virreinato del Perú en el siglo XVII. Lima: Banco Central de la Reserva de Perú e Instituto de Estudios Peruanos, 2011.

ANDÚJAR CASTILLO, Francisco. "Gastos secretos y venalidad en el siglo XVII". En Herederas de Clío. Mujeres que han impulsado la Historia, editado por Gloria Franco Rubio y María Ángeles Pérez Samper. Sevilla: Mergablum, 2014.

"Hacerse noble a finales del siglo XVII. Las contradicciones de la jerarquía nobiliaria”. En Construyendo Historia. Estudios en torno a Juan Luis Castellano, editado por Antonio Jiménez Estrella, Julián J. Lozano Navarro, Francisco Sánchez-Montes González y Margarita Ma Birriel Salcedo. Granada: Universidad de Granada, 2013.

BASADRE Grohmann, Jorge. El conde de Lemos y su tiempo. Lima: ed. Huascarán, 1948.

BURKHOLDER, Mark, y Chandler, D.S. De la impotencia a la autoridad. La Corona española y las Audiencias en América, 1687-1808. México: Fondo de Cultura Económica, 1984.

BUSTO Duthurburu, José Antonio del. "Los virreyes: vida y obra”. En Historia General del Perú, editado por Guillermo Lohmann Villena y José Antonio del Busto Duthurburu. Lima: Brasa, 1994.

DOMÍNGUEZ Ortiz, Antonio. "Un virreinato en venta". Mercurio Peruano no. 453 (1965): 43-51.

La sociedad española en el siglo XVII, vol. 1. Madrid: Consejo Superior de Investigaciones Científicas, 1992.

Política y hacienda de Felipe IV. Madrid: Derecho Financiero, 1960.

FELICES DE LA FUENTE, María del Mar. "Recompensar servicios con honores: el crecimiento de la nobleza titulada en los reinados de Felipe IV y Carlos II". Studia Historica, Historia Moderna no. 35 (2013): 409-435.

"Silencio y ocultaciones en los despachos de los títulos nobiliarios.

Análisis crítico de su contenido”. Chronica Nova XXXVI (2010): 229-252.

GIMÉNEZ Carrillo, Domingo Marcos. "La venta de hábitos de las órdenes militares en el siglo XVII. Entre la ocultación y el delito de simonía”. En El poder del dinero. Ventas 
de cargos y honores en el Antiguo Régimen, editado por Francisco Andújar Castillo y María del Mar Felices de la Fuente. Madrid: Biblioteca Nueva, 2011.

HANKE, Lewis, y Rodríguez, Celso. Los virreyes españoles en América durante el gobierno de la casa de Austria, Perú, vol. VII. Madrid: Atlas, 1980.

JIMÉNEZ Jiménez, Ismael. "Nacimiento y primeros pasos de un nuevo título de Castilla: el marquesado del Moscoso”. En El cardenal Portocarrero y su tiempo (1635-1709). Biografías estelares y procesos influyentes, coordinado por José Manuel de Bernardo Ares. Córdoba: CSED Historia, 2013.

"Niños con poder: mandos pueriles en el Virreinato del Perú en la segunda mitad del siglo XVII”. En Temas americanistas: historia y diversidad cultural, coordinado por Sandra Olivero Guidobono y José Luis Caño Ortigosa. Sevilla: Universidad de Sevilla y Diputación Provincial de Sevilla, 2015.

KAMEN, Henry. La España de Carlos II. Barcelona: Crítica, 1981.

LATASA Vassallo, Pilar. "La corte virreinal peruana: perspectivas de análisis (siglos XVI y XVII)”. En El gobierno de un mundo: virreinatos y audiencias en la América hispánica, coordinado por Feliciano Barrios Pintado. Cuenca: Universidad de Castilla La Mancha, 2004.

LOHMANN Villena, Guillermo. "Notas sobre el conde de Cañete, virrey del Perú". Revista de Indias no. III (1942): 551-558.

El conde de Lemos. Virrey del Perú. Madrid: Escuela de Estudios Hispanoamericanos, 1946.

Los americanos en las órdenes nobiliarias, t. I. Madrid: Consejo Superior de Investigaciones Científicas, 1993.

MARURI Villanueva, Ramón. "Poder con poder se paga: títulos nobiliarios beneficiados en Indias (1681-1821)". Revista de Indias no. LXIX, (2009): 207-240.

MORENO Cebrián, Alfredo. "Venta y beneficios de los corregimientos peruanos". Revista de Indias XXXVI (1976): 213-246.

O’PHELAN, Scarlett. “Orden y control en el siglo XVIII. La política borbónica frente a la corrupción fiscal, comercial y administrativa". En El pacto infame. Estudios sobre la corrupción en el Perú, editado por Felipe Portocarrero Suárez. Lima: Pontificia Universidad Católica del Perú, Universidad del Pacífico e Instituto de Estudios Peruanos, 2005. 
TEMPUS Revista en Historia General

PIETSCHMANN, Horts. "Burocracia y corrupción en Hispanoamérica colonial. Una aproximación tentativa". Nova americana no. 5 (1982): 11-37.

PONCE-LEIVA, Pilar. "El valor de los méritos. Teoría y práctica política en la provisión de oficios (Quito, 1675-1700)”. Revista de Indias no. LXXIII (2013): 341-364.

RODRÍGUEZ Hernández, Antonio José. "La creación de títulos de Castilla durante los reinados de Felipe IV y Carlos II: concesiones y ritmos". En Casas, familias y rentas. La nobleza del reino de Granada entre los siglos XV-XVIII, editado por Julián Pablo Díaz López, Francisco Andújar Castillo y Ángel Galán Sánchez. Granada: Universidad de Granada, 2010.

SANZ Tapia, Ángel. ¿Corrupción o necesidad? La venta de cargos de gobierno americanos bajo Carlos II (1674-1700). Madrid: Consejo Superior de Investigaciones Científicas, 2009.

"El proceso de venta y beneficio de cargos indianos en el siglo XVII".

En La venta de cargos y el ejercicio del poder en Indias, coordinado por Julián Bautista Ruiz Rivera y Ángel Sanz Tapia. León: Universidad de León, 2007.

"La venta de oficios de hacienda en la Audiencia de Quito (1650-1700)".

Revista de Indias no. LXIII (2003): 633-648.

SCHÄFER, Ernst. El Consejo Real y Supremo de las Indias. Su historia, organización y labor administrativa hasta la terminación de la casa de Austria. Sevilla: Imp. M. Carmona, 1935

SERRERA Contreras, Ramón María. "Geografía y poder en el siglo XVII indiano: el factor distancia en el incumplimiento de la norma". En Libro homenaje "in memoriam" Carlos Díaz Rementería, VV.AA. Huelva: Secretariado de Publicaciones de la Universidad de Huelva, 1998.

Soria Mesa, Enrique. La nobleza en la España moderna: cambio y continuidad. Madrid, Marcial Pons, 2007. 